\title{
kNACking on heaven's door: how important are NAC transcription factors for leaf senescence and Fe/Zn remobilization to seeds?
}

\author{
Felipe Klein Ricachenevsky ${ }^{1}$, Paloma Koprovski Menguer ${ }^{\mathbf{2}}$ and Raul Antonio Sperotto ${ }^{\mathbf{*}}$ * \\ 1 Centro de Biotecnologia, Universidade Federal do Rio Grande do Sul, Porto Alegre, Rio Grande do Sul, Brazil \\ ${ }^{2}$ Departamento de Botânica, Universidade Federal do Rio Grande do Sul, Porto Alegre, Rio Grande do Sul, Brazil \\ ${ }^{3}$ Centro de Ciências Biológicas e da Saúde, Programa de Pós-Graduação em Biotecnologia, Centro Universitário UNIVATES, Lajeado, \\ Rio Grande do Sul, Brazil
}

\section{Edited by:}

Michael A. Grusak, United States Department of Agriculture-Agricultural Research Service, Children's Nutrition Research Center, USA

\section{Reviewed by:}

Trevor Garnett, Australian Centre for Plant Functional Genomics, Australia Christina B. Garcia, Baylor College of Medicine, USA

\section{${ }^{*}$ Correspondence:}

Raul Antonio Sperotto, Centro de Ciências Biológicas e da Saúde,

Programa de Pós-Graduação em

Biotecnologia, Centro Universitário

UNIVATES, Rua Avelino Tallini 171,

Lajeado, Rio Grande do Sul

95.900-000, Brazil

e-mail: rasperotto@univates.br
Senescence is a coordinated process where a plant, or a part of it, engages in programmed cell death to salvage nutrients by remobilizing them to younger tissues or to developing seeds. As $\mathrm{Fe}$ and $\mathrm{Zn}$ deficiency are the two major nutritional disorders in humans, increased concentration of these nutrients through biofortification in cereal grains is a long-sought goal. Recent evidences point to a link between the onset of leaf senescence and increased $\mathrm{Fe}$ and $\mathrm{Zn}$ remobilization. In wheat, one member of the NAC (NAM, ATAF, and $\mathrm{CUC}$ ) transcription factor (TF) family (NAM-B1) has a major role in the process, probably regulating key genes for the early onset of senescence, which results in higher Fe and $\mathrm{Zn}$ concentrations in grains. In rice, the most important staple food for nearly half of the world population, the NAM-B1 ortholog does not have the same function. However, other NAC proteins are related to senescence, and could be playing roles on the same remobilization pathway. Thus, these genes are potential tools for biofortification strategies in rice. Here we review the current knowledge on the relationship between senescence, Fe and Zn remobilization and the role of NAC TFs, with special attention to rice. We also propose a working model for OsNAC5, which would act on the regulation of nicotianamine (NA) synthesis and metal-NA remobilization.

Keywords: biofortification, iron, NAC transcription factor, nutrient remobilization, senescence, zinc

\section{Fe AND Zn BIOFORTIFICATION}

Iron $(\mathrm{Fe})$ and zinc $(\mathrm{Zn})$ are essential micronutrients for almost all living organisms and are two of the most versatile metals in biology. Fe participates as a catalytic cofactor in multiple metabolic pathways (photosynthesis, respiration, hormone synthesis, nitrogen fixation, DNA synthesis and repair) due to the ability to participate on reversible redox reactions as $\mathrm{Fe}^{2+}$ (ferrous) and $\mathrm{Fe}^{3+}$ (ferric) ions (Puig et al., 2007). Zn does not participate directly on redox reactions, since it occurs in a single oxidation state, but is a key structural component of around 300 enzymes and 2,000 transcription factors (TFs; Palmgren et al., 2008; Prasad, 2012). Both Fe and $\mathrm{Zn}$ are present in low quantities in most plant staple foods, leading to $\mathrm{Fe}$ and $\mathrm{Zn}$ deficiency in humans. Malnutrition of these micronutrients are leading risk factors for disability and death worldwide, especially to children eating cereal-based diets, with low intake of micronutrient-rich foods as meat, poultry, fish, fruits, legumes, and vegetables.

Strategies to alleviate micronutrient malnutrition include fortification (addition during food processing) and supplementation (ingestion of pills or sachets). Although somewhat successful, these approaches are not widely accessible due to logistic and economic issues. A very cost-effective alternative is biofortification, the increase of bioavailable concentrations of an element in edible portions of crops before harvesting (for comprehensive reviews see White and Broadley, 2005; Sperotto et al., 2012a; Carvalho and Vasconcelos, 2013).

Biofortification includes different approaches like soil fertilization or foliar application, conventional breeding and/or transgenic strategies. Mineral fertilization is an effective method to increase seed mineral concentrations, but can be problematic due to continuous cost and environmental carryover. Conventional breeding has been used for decades. Although there is genetic diversity available within existing germplasm collections, rice seems to have the narrowest range, making substantial increases in Fe and $\mathrm{Zn}$ concentrations more difficult compared to maize and wheat (Kennedy and Burlingame, 2003; Gómez-Galera et al., 2010; Sperotto et al., 2012a). Thus, it seems imperative that transgenic approaches be used to enable significant increases in $\mathrm{Fe}$ and $\mathrm{Zn}$ content and bioavailability.

Single or multiple-transgene insertions into the rice genome have successfully increased $\mathrm{Fe}$ concentration in grains. Independent over-expression of OsNAS genes produced the most promising results so far (Johnson et al., 2011), while other multitransgene approaches also increased grain Fe concentration (Wirth et al., 2009; Masuda et al., 2012). However, except in the study from Johnson et al. (2011), the levels are still not effective enough to impact human nutrition. An unexplored avenue would be the controlled expression of regulatory genes involved in key processes to $\mathrm{Fe}$ and $\mathrm{Zn}$ seed allocation. This approach has already 
been performed to generate rice plants more resistant to Fe deficiency (Kobayashi et al., 2007; Ogo et al., 2011). In order to do that for mineral concentrations in grains, we still need to identify the molecular players relevant to their transport within the plant and during remobilization.

\section{SENESCENCE PROCESSES: WHAT, WHEN, AND HOW?}

Senescence represents endogenously degenerative processes which ultimately lead to organ death. However, it is not a passive process (Yoshida, 2003), but rather a series of coordinated and controlled events. Decline of photosynthesis, chloroplast and chlorophyll degradation, dismantling of biomolecules and decrease in cellular metabolic activities take place, which result in available nutrients and metabolites that can be transported from source (the tissue that supplies nutrients, most commonly green tissues) to sink (the net importer of nutrients, younger or reproductive organs) through the vascular system (Thomas, 2013). Part of leaf senescence seems to be regulated by sugar levels (Rolland et al., 2006; Sperotto et al., 2007), since a senescence-related loss of chlorophyll or protein can be induced by increased sugar contents (Wingler et al., 1998). Hormones and nutrients also contribute to regulation of senescence in source tissues, especially cytokinins, which have a senescence-delaying effect (Sperotto et al., 2009; Davies and Gan, 2012).

The source-sink signaling is not fully understood, and it depends on the species and circumstances. It is already known that senescence in source leaves can be delayed by removal of strong sinks (Zavaleta-Mancera et al., 1999). Elevated levels of $\mathrm{N}$ alter sugar signaling in source leaves (Thomas, 2013) and have a significant impact on $\mathrm{Fe}$ and $\mathrm{Zn}$ acquisition and grain allocation in wheat (Kutman et al., 2011). According to Shi et al. (2012), a sufficient $\mathrm{N}$ supply inhibits Fe export from source leaves, but $\mathrm{N}$ deficiency enhances Fe pools in source leaves and stimulates Fe export from senescing leaves to sink tissues in barley, corroborating previous findings that high protein concentrations in $\mathrm{N}$-fertilized leaves tend to immobilize Fe and delay senescence (Marschner, 1995).

Nitrogen remobilization from source tissues to seeds (Hortensteiner and Feller, 2002) has received much more attention than metal remobilization over the last decades, since grain yield has been treated as the most important trait to be improved. Part of the seed $\mathrm{N}$ is acquired by the roots, but $\mathrm{N}$ remobilization from almost all vegetative organs also contributes to the seed $\mathrm{N}$ loading, especially during senescence processes (Burstin et al., 2007). In this way, the senescence process partly satisfies grain $\mathrm{N}$ concentration, as well with other minerals (Himelblau and Amasino, 2001). However, it is already known that application of fertilizer $\mathrm{N}$ generally decreases whole-plant remobilization efficiency (Bahrani et al., 2011).

Previous work has shown that although seed minerals are partially supplied by continuous uptake and translocation during reproductive growth, remobilization of previous stored minerals in green source tissues is also important (Jiang et al., 2007; Waters and Grusak, 2008; Sperotto et al., 2012b), as commonly seen for N. In rice, it was shown that Fe remobilization is dependent on Fe status: under low or sufficient Fe supply, flag leaf Fe remobilization is observed; under high but non-toxic Fe concentrations, there is no Fe remobilization, presumably because of continuous root uptake
(Sperotto et al., 2012b). It is also known that mineral remobilization from leaves to seeds can be enhanced by senescence (Zhang et al., 1995; Uauy et al., 2006; Distelfeld et al., 2007; Shi et al., 2012). As several proteins include Fe and $\mathrm{Zn}$ ions, a substantial level of metals can be released during leaf senescence due to the high level of protein degradation (Waters et al., 2009).

Recent molecular studies have shown that senescence processes are driven by TF networks that regulate the expression of several senescence-related genes (Guo et al., 2004; Lin and Wu, 2004). One of the most important families of genes described as associated with senescence, and also with nutrient remobilization from source organs to developing seeds, is the NAC (NAM, ATAF, and CUC) family of TFs (Guo etal., 2004; Uauy et al., 2006).

\section{NAC TRANSCRIPTION FACTORS}

Proteins of the NAC family are one of the largest classes of plantspecific TFs. Roles of many NAC TFs have been demonstrated in diverse plant developmental processes. The earliest reports include the NAM (non-apical meristem) protein from petunia (Petunia hybrida); nam mutants lack the shoot apical meristem (SAM) and die at the seedling stage (Souer et al., 1996). The CUC1/CUC2 (cup-shaped cotyledon) TF from Arabidopsis, which participates in the development of embryos and flowers (Aida et al., 1997), defines the boundary domain around organs in the meristem (Nikovics et al., 2006). Later, NAC proteins have been related to diverse processes such as auxin and ethylene signaling (He et al., 2005; Park et al., 2011), cell wall formation (Wang et al., 2011), biotic and abiotic stresses (Puranik et al., 2012), and senescence (Kou et al., 2012).

NAC proteins contain a highly conserved N-terminal domain known as the NAC domain, which has been implicated in DNA binding (Duval et al., 2002; Ernst et al., 2004) as well as proteinprotein interactions, forming homodimers or heterodimers with TFs from the NAC family (Ernst et al., 2004; Jeong et al., 2009) or other families (Xie et al., 2000; Greve et al., 2003). The NAC domain reveals a fold consisting of a twisted beta-sheet surrounded by a few helical elements (Ernst et al., 2004). On the other hand, C-terminal regions of NAC proteins are highly divergent (Olsen et al., 2005; Fang et al., 2008), and are related to transcriptional regulation (Xie et al., 2000; Duval et al., 2002).

Many NAC genes have been involved in responses to various environmental stresses like drought, cold, salinity, pathogen attack, and wounding. For recent reviews on NAC TFs in stress response, see Nakashima et al. (2012) and Puranik et al. (2012). In rice, the stress-responsive NAC group (SNAC) includes some already characterized members. OsNAC5, OsNAC6, and OsNAC10 are induced by abiotic stresses, abscisic acid (ABA), and methyl jasmonic acid, a plant hormone that activates defense responses against herbivores and pathogens (Ohnishi et al., 2005; Sperotto et al., 2009; Jeong et al., 2010; Takasaki et al., 2010; Song et al., 2011); OsNAC6 is also induced by biotic stresses (such as wounding and blast disease; Nakashima et al., 2007). Rice plants over-expressing either OsNAC5, OsNAC9, or OsNAC10 under the control of the rootspecific RCc3 promoter improved tolerance to abiotic stresses during the vegetative stage of growth and, most importantly, at the reproductive stage, with a concomitant increase in grain 
yield (Jeong et al., 2010, 2013; Redillas et al., 2012). Another characterized SNAC from rice, OsNAC4, was proposed to lead to hypersensitive response in plants after an appropriate pathogen recognition signal is encountered (Kaneda et al., 2009). In Arabidopsis, the SNAC genes ANAC019, ANAC055, and ANAC072 are induced by pathogen attack and wounding, and transgenic plants over-expressing either one showed a significant increase in drought tolerance (Tran et al., 2004). Considering that these proteins group with the rice paralogs SNAC1, OsNAC3, OsNAC4, OsNAC5, and OsNAC6, their function seems to be conserved.

Several members of the NAC family have been functionally characterized as playing a prominent role in leaf senescence. In Arabidopsis, almost one-fifth of the predicted 109 NAC members are in the database of senescence leaf expression sequence tags (dbEST; Guo et al., 2004). Characterization of NAC TFs involved in senescence processes is also available for other plant species, like rice OsNAC5 (Sperotto et al., 2009); wheat NAM-B1 (Uauy et al., 2006); and bamboo BeNAC1 (Chen et al., 2011). The relation between NAC TFs, senescence and nutrient remobilization will be discussed in the next section.

\section{SENESCENCE AND METAL REMOBILIZATION: ARE NAC TRANSCRIPTION FACTORS BRIDGING THE GAP?}

In monocarpic plants such as wheat and rice, whole-plant senescence is a coordinated process where catabolic activity provides nutrients that are exported and remobilized to developing grains (Matile et al., 1996; Hortensteiner and Feller, 2002). The Gpc-B1 quantitative trait loci (QTL) from wild emmer wheat (Triticum turgidum ssp. dicoccoides) was first described as conferring high grain protein content in wheat across diverse environments (Chee et al., 2001; Olmos et al., 2003), an important trait for improving bread and pasta quality. Although already mapped and used in breeding programs, $G p c-B 1$ locus was cloned later by Uauy et al. (2006), which found the causal gene to be a NAC TF, NAM-B1. NAM-B1 expression is up-regulated after anthesis in flag leaves and accelerates senescence. In modern wheat varieties, a 1-bp frame-shift insertion at the NAM-B1 coding sequence results in a truncated version of the protein, while the wild relative has an intact, fully functional NAM-B1. Silencing of NAM-B1 and other NAM paralogs mimicked the insertion effect, resulting in delayed senescence, decreased grain protein, and lower Fe and $\mathrm{Zn}$ concentrations due to reduced nutrient remobilization from vegetative tissues (Uauy et al., 2006; Waters et al., 2009). Moreover, a transcriptomic study showed enrichment of sequences related to transport in wild-type (WT) compared to NAM-B1 RNA interference (RNAi) lines during senescence (Cantu et al., 2011). Taken together, these results established NAM-B1 as a positive regulator of senescence and nutrient remobilization during grain maturation, suggesting that an early senescence onset could lead to increased Fe and Zn concentrations in grains (Uauy et al., 2006).

To describe genes with similar functions in other crops, an obvious avenue would be looking at orthologous proteins. The closest homolog of NAM-B1 in the rice genome, named ONAC010 (LOC_Os07g3792; Uauy et al., 2006), has a function in flower development but not in senescence, as neither ONAC010 lossof-function nor over-expression have the expected effects on senescence timing (Distelfeld et al., 2012). Thus, another paralog with lower sequence similarity could play the NAM-B1 role in rice plants. In this context, OsNAC5 was demonstrated to be a senescence associated gene that is up-regulated during grain maturation in rice flag leaves (Sperotto et al., 2009). OsNAC5 is regulated by $\mathrm{ABA}$, a hormone with a known central role in senescence processes (Lim et al., 2007). A comparison of diverse cultivars showed a positive correlation of OsNAC5 expression in flag leaves before and during anthesis with final $\mathrm{Fe}, \mathrm{Zn}$, and protein concentrations in mature grains (Sperotto et al., 2009, 2010). These results showed that OsNAC5 expression pattern resembles that of NAM-B1, and suggested that OsNAC5 could act during senescence-associated nutrient remobilization to rice grains, probably downstream on the senescence onset pathway.

Transgenic plants bearing constructs with OsNAC5 under the control of a constitutive or a root-specific promoter were generated in a recent work. When OsNAC5 was expressed only in roots, plants increased root diameter and improved recovery after drought stress (Jeong et al., 2013). Interestingly, transcriptomic analysis of roots from both transgenic lines showed commonly up-regulated genes, indicating potential targets of OsNAC5, but not necessarily linked to changes in root morphology (Jeong et al., 2013). Among them, Nicotianamine Synthase 2 (OsNAS2) and Yellow Stripe-Like 2(OsYSL2), two genes related to metal homeostasis, were up-regulated. OsNAS2 is a key enzyme in nicotianamine (NA) synthesis, a low-molecular weight compound that chelates metals and a precursor for phytosiderophore synthesis (Higuchi et al., 1999), while OsYSL2 is an Fe-NA transporter expressed in phloem cells (Koike et al., 2004). Both NA and OsYSL2 are involved in Fe seed loading and metal long distance transport through the phloem (Koike et al., 2004; Curie et al., 2009; Klatte et al., 2009; Ishimaru et al., 2010; Schuler et al., 2012).

Different studies point that regulation of NA synthesis and metal-NA complex transporters could be involved in remobilization. Constitutive over-expression or activation-tagging of OsNAS1, OsNAS2, or OsNAS3 genes in rice increased concentrations of Fe, Zn, or both in grains (Lee et al., 2009, 2011, 2012; Johnson et al., 2011). Concomitant insertion of constructs driving Hordeum vulgare NAS1 constitutive expression, OsYSL2 expression in phloem cells and endosperm and Ferritin in endosperm, led to increased Fe concentrations (and $\mathrm{Zn}$ to a lower extent) in grains (Masuda et al., 2012). In H. vulgare, both dark and $\mathrm{N}$ deficiency-induced senescence up-regulated HvNAS2 expression in leaves, resulting in increased phytosiderophore concentration rather than NA (Shi et al., 2012). In A. thaliana, loss-of-function of OsYSL2 homologs, AtYSL1 and AtYSL3, resulted in reduced remobilization of metals to seeds during senescence (Waters et al., 2006).

Therefore, we speculate that OsNAC5 has a role in senescence and metal movement to grains by controlling, either directly or indirectly, the biosynthesis of NA and metal transport through the phloem. Our proposed model, based on data from the literature, is shown in Figure 1: (A) a senescence signal is sensed by the cell, activating signaling molecules that regulate the onset of senescence; (B) OsNAC5 transcription is up-regulated as part of the senescence-induced nutrient remobilization process; (C) OsNAC5 protein up-regulates, either directly or indirectly, OsNAS2 and OsYSL2 transcription, as well as other targets (not necessarily 


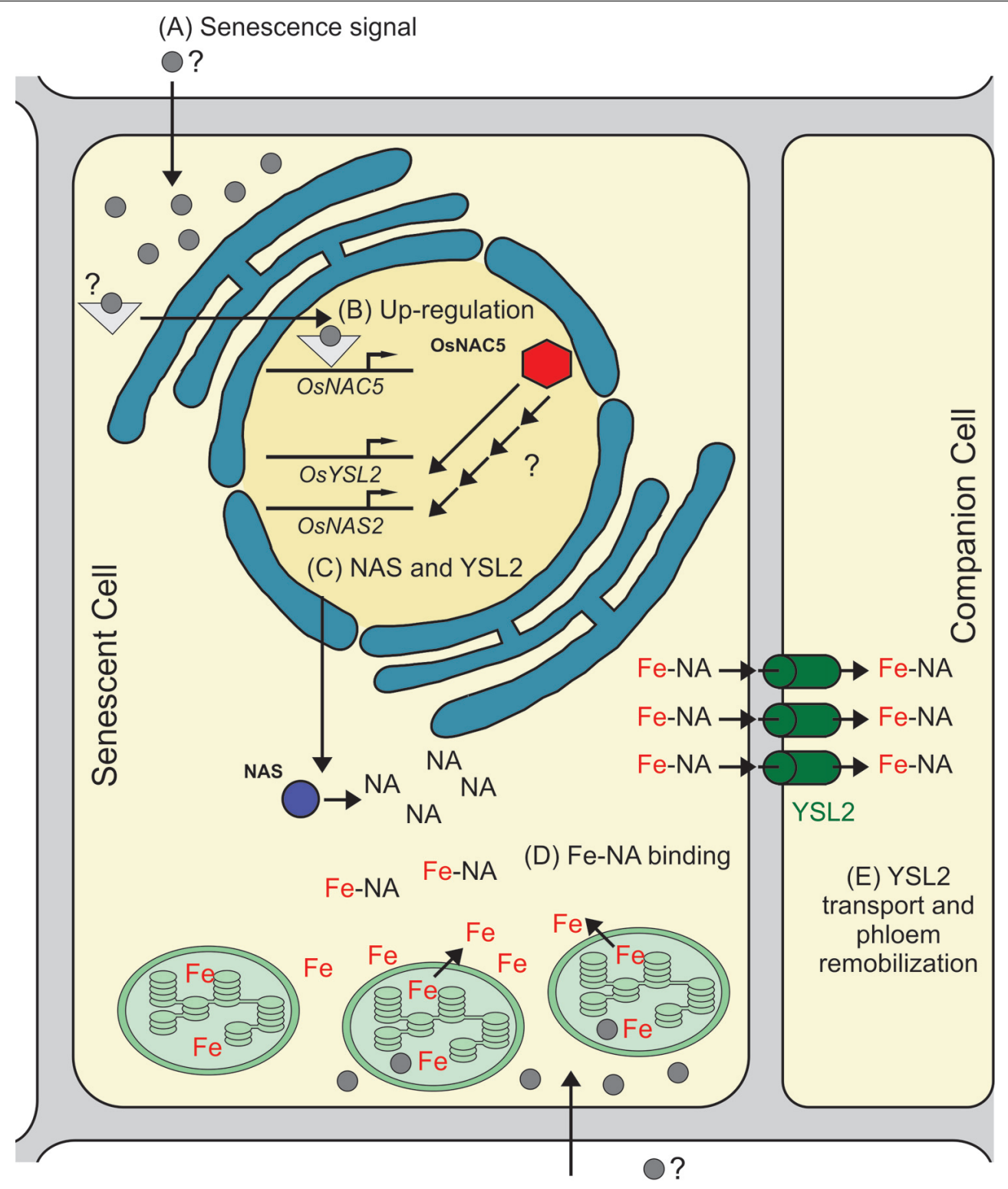

(A) Senescence signal

FIGURE 1 | Proposed model for OsNAC5 role in senescence and metal remobilization. The model is based on indirect evidence provided by several studies, especially on Sperotto et al. (2009) and Jeong et al. (2013), and shows only Fe remobilization, although a similar pathway is likely to be involved in $\mathrm{Zn}$ and other metals remobilization. (A) A signal is sensed by the cell, triggering the senescence-associated cellular components degradation, including chloroplasts, the main site of Fe concentration in the cell. (B) OsNAC5 transcription is up-regulated by the senescence downstream signaling pathway. (C) OsNAC5 protein is produced and triggers the up-regulation of OsNAS2 and OsYSL2 transcription (based on microarray data presented in the work performed by Jeong et al., 2013). The increased transcription observed is either directly or indirectly regulated by OsNAC5. (D) OsNAS2 protein increases intracellular NA concentration, which in turn chelates free Fe coming from chloroplast and other cellular components degradation.

(E) The Fe-NA complex is transported across the plasma membrane of the senescent cell, and then transported into phloem by OsYSL2, which allows Fe-NA complex long distance translocation. It is important to point the possibility that Fe and NA are exported independently from the cell, interacting in the apoplast and then transported into the phloem by OsYSL2 related to metal remobilization); (D) OsNAS2 increases NA production, which binds free Fe coming from cellular degradation; (E) after efflux from the cell, OsYSL2 acquires the Fe-NA complex into phloem cells for long distance transport. It is important to note that, while OsYSL2 was not demonstrated to transport ZnNA complexes, NA is able to bind $\mathrm{Zn}^{2+}$, and $\mathrm{Zn}-\mathrm{NA}$ complexes are the major $\mathrm{Zn}$ form found in the rice phloem sap (Nishiyama et al., 2012). Thus, other transporters could be playing a similar role to OsYSL2 to load Zn-NA into the phloem.

However, work analyzing distinct OsNAC5 over-expressing lines did not show up-regulation of OsNAS2 or OsYSL2 (Takasaki etal., 2010). We should consider that the increased 
expression observed by Jeong etal. (2013) was a result from roots transcriptomic analyses, which is not the tissue where remobilization takes place. Moreover, up-regulation of these genes could be an indirect effect rather than a result of OsNAC5 binding to OsNAS2 or OsYSL2 promoters.

Transcriptomic analysis of NAM-B1 RNAi wheat lines did not reveal down-regulation of homologous sequences to NAS2 or YSL2 compared to WT, but rather putative ZIP (zinc-regulated/ironregulated transporter) and NRAMP (natural resistance associated macrophage protein) metal transporters (Cantu et al., 2011), indicating that NAS and YSL homologs are not regulated by NAM-B1. This could be due to the fact that NAM-B1 and OsNAC5 are not necessarily regulating the same set of genes. NAM-B1 silencing leads to late senescence, while the functional version from wheat wild relative accelerates it. On the other hand, OsNAC5 overexpressing plants were not reported as senescing earlier than WT (Takasaki et al., 2010; Song et al., 2011; Jeong et al., 2013), indicating that OsNAC5 increased expression cannot trigger senescence alone. Silencing of OsNAC5 did not lead to late senescence as well

\section{REFERENCES}

Aida, M., Ishida, T., Fukaki, H., Fujisawa, H., and Tasaka, M. (1997). Genes involved in organ separation in Arabidopsis: an analysis of the cupshaped cotyledon mutant. Plant Cell 9, 841-857. doi: 10.1105/tpc.9.6.841

Bahrani, A., Heidari, H., Abad, S., and Aynehband, A. (2011). Nitrogen remobilization in wheat as influenced by nitrogen application and postanthesis water deficit during grain filling. Afr. J. Biotechnol. 10, 10585 10594. doi: 10.5897/AJB11.013

Burstin, J., Marget, P., Huart, M., Moessner, A., Mangin, B., Duchene, C., et al. (2007). Developmental genes have pleiotropic effects on plant morphology and source capacity, eventually impacting on seed protein content and productivity in pea. Plant Physiol. 144, 768-781. doi: 10.1104/pp.107.096966

Cantu, D., Pearce, S. P., Distelfeld, A., Christiansen, M. W., Uauy, C., Akhunov, E., et al. (2011). Effect of the down-regulation of the high Grain Protein Content (GPC) genes on the wheat transcriptome during monocarpic senescence. BMC Genomics 12:492. doi: 10.1186/14712164-12-492

Carvalho, S. M. P., and Vasconcelos, M. W. (2013). Producing more with less: strategies and novel technologies for plant-based food biofortification. Food Res. Int. (in press). doi: 10.1016/j.foodres.2012. 12.021

Chee, P. W., Elias, E. M., Anderson, J. A., and Kianian, S. F. (2001). Evaluation of a high grain protein QTL from Triticum turgidum L. var. dicoccoides in an adapted durum wheat background. Crop Sci. 41, 295-301. doi: 10.2135/cropsci2001. 412295x

Chen, Y., Qiu, K., Kuai, B., and Ding, Y. (2011). Identification of an NAP-like transcription factor BeNAC1 regulating leaf senescence in bamboo (Bambusa emeiensis 'Viridiflavus'). Physiol. Plant. 42, 361371. doi: 10.1111/j.1399-3054.2011. 01472.x

Curie, C., Cassin, G., Couch, D., Divol, F., Higuchi, K., Le Jean, M., et al. (2009). Metal movement within the plant: contribution of nicotianamine and yellow stripe 1like transporters. Ann. Bot. 103, 1-11. doi: 10.1093/aob/mcn207

Davies, P. J., and Gan, S. (2012) Towards an integrated view of monocarpic plant senescence. Russian J. Plant Physiol. 59, 467-478. doi: 10.1134/S102144371204005X

Distelfeld, A., Cakmak, I., Peleg, Z., Ozturk, L., Yazici, A. M., Budak, H., et al. (2007). Multiple QTL-effects of wheat $\mathrm{Gpc}-\mathrm{B} 1$ locus on grain protein and micronutrient concentrations. Physiol. Plant. 129, 635643. doi: 10.1111/j.1399-3054.2006. 00841.x

Distelfeld, A., Pearce, S. P., Avni, R., Scherer, B., Uauy, C., Piston, F., et al. (2012). Divergent functions of orthologous NAC transcription factors in wheat and rice. Plant Mol. Biol. 78, 515-524. doi: 10.1007/s11103012-9881-6

Duval, M., Hsieh, T. F., Kim, S. Y. and Thomas, T. L. (2002). Molecular characterization of AtNAM: a member of the Arabidopsis NAC domain superfamily. Plant Mol. Biol. 50, 237 248. doi: 10.1023/A:1016028530943

(Song et al., 2011). OsNAC5 is known to homo- and heterodimerize with other TFs (Jeong et al., 2009), which could be necessary for OsNAC5-mediated response. Thus, it seems that OsNAC5 is acting more downstream on the senescence pathway than NAM$\mathrm{B} 1$, or even in a distinct parallel regulatory network, regulating a different set of senescence-related processes.

Although we should be cautious in the analysis of the available evidence, our model seems to be holding as the first attempt to point out the mechanism of NAC proteins in mineral remobilization in crops. Further work will be necessary to clearly elucidate the role of OsNAC5 in senescence and metal remobilization, as well to functionally demonstrate which genes are controlled by this TF. If true, the regulation of metal remobilization by OsNAC 5 could be an interesting avenue for biofortification strategies.

\section{ACKNOWLEDGMENTS}

We are grateful to Janette Palma Fett and Marta Wilton Vasconcelos for critical reading of the manuscript.

Ernst, H. A., Olsen, A. N., Larsen, S., and Lo Leggio, L. (2004). Structure of the conserved domain of ANAC, a member of the NAC family of transcription factors. EMBO Rep. 5, 297-303. doi: 10.1038/sj.embor. 7400093

Fang, Y., You, J., Xie, K., Xie, W., and Xiong, L. (2008). Systematic sequence analysis and identification of tissue-specific or stress-responsive genes of NAC transcription factor family in rice. Mol. Genet. Genomics 280, 547-563. doi: 10.1007/s00438008-0386-6

Gómez-Galera, S., Rojas, E., Sudhakar D., Zhu, C., Pelacho, A. M., Capell, T., et al. (2010). Critical evaluation of strategies for mineral fortification of staple food crops. Transgenic Res. 19, 165-180. doi: 10.1007/s11248-0099311-y

Greve, K., La Cour, T., Jensen, M. K., Poulsen, F. M., and Skriver, K. (2003). Interactions between plant RING-H2 and plant-specific NAC (NAM/ATAF1/2/CUC2) proteins: RING-H2 molecular specificity and cellular localization. Biochem. J. 371, 97-108. doi: 10.1042/BJ20021123

Guo, Y., Cai, Z., and Gan, S. (2004). Transcriptome of Arabidopsis leaf senescence. Plant Cell Environ. 27, 521-549. doi: 10.1111/j.13653040.2003.01158.x

He, X. J., Mu, R. L., Cao, W. H., Zhang, Z. G., Zhang, J. S., and Chen, S. Y. (2005). AtNAC2, a transcription factor downstream of ethylene and auxin signaling pathways, is involved in salt stress response and lateral root development. Plant J. 44, 903-916. doi: $10.1111 / \mathrm{j} .1365$ 313X.2005.02575.x
Higuchi, K., Suzuki, K., Nakanishi, H., Yamaguchi, H., Nishizawa, N. K., and Mori, S. (1999). Cloning of nicotianamine synthase genes, novel genes involved in the biosynthesis of phytosiderophores. Plant Physiol. 119, 471-480. doi: 10.1104/pp.119.2.471

Himelblau, E., and Amasino, R. M. (2001). Nutrients mobilized from leaves of Arabidopsis thaliana during leaf senescence. J. Plant Physiol. 158, 1317-1323. doi: 10.1078/0176-161700608

Hortensteiner, S., and Feller, U. (2002). Nitrogen metabolism and remobilization during senescence. J. Exp. Bot. 53, 927-937. doi: 10.1093/jexbot/53.370.927

Ishimaru, Y., Masuda, H., Bashir, K., Inoue, H., Tsukamoto, T., Takahashi, M., et al. (2010). Rice metal-nicotianamine transporter, OsYSL2, is required for the longdistance transport of iron and manganese. Plant J. 62, 379-390. doi: $\quad$ 10.1111/j.1365-313X.2010. 04158.x

Jeong, J. S., Kim, Y. S., Baek, K. H., Jung, H., Ha, S. H., Choi, Y. D., et al. (2010). Root-specific expression of OsNAC10 improves drought tolerance and grain yield in rice under field drought conditions. Plant Physiol. 153, 185-197. doi: 10.1104/pp.110.154773

Jeong, J. S., Kim, Y. S., Redillas, M. C., Jang, G., Jung, H., Bang, S. W., et al. (2013). OsNAC5 overexpression enlarges root diameter in rice plants leading to enhanced drought tolerance and increased grain yield in the field. Plant Biotechnol. J. 11, 101-114. doi: $10.1111 /$ pbi.12011 
Jeong, J. S., Park, Y. T., Jung, H., Park, S. H., and Kim, J. K. (2009). Rice NAC proteins act as homodimers and heterodimers. Plant Biotechnol. Rep. 3, 127-134. doi: 10.1007/s11816-0090081-z

Jiang, W., Struik, P. C., Lingna, J., van Keulen, H., Ming, Z., and Stomph, T. J. (2007). Uptake and distribution of root-applied or foliar-applied $65 \mathrm{Zn}$ after flowering in aerobic rice. Ann. Appl. Biol. 150, 383-391. doi: 10.1111/j.1744-7348.2007.00138.x

Johnson, A. A., Kyriacou, B., Callahan, D. L., Carruthers, L., Stangoulis, J., Lombi, E., et al. (2011). Constitutive overexpression of the OsNAS gene family reveals singlegene strategies for effective ironand zinc-biofortification of rice endosperm. PLoS ONE 6:e24476. doi: 10.1371/journal.pone.0024476

Kaneda, T., Taga, Y., Takai, R., Iwano, M., Matsui, H., Takayama, S., et al. (2009). The transcription factor OsNAC4 is a key positive regulator of plant hypersensitive cell death. EMBO J. 28, 926-936. doi: 10.1038/emboj.2009.39

Kennedy, G., and Burlingame, B. (2003). Analysis of food composition data on rice from a plant genetic resources perspective. Food Chem. 80, 589596. doi: 10.1016/S0308-8146(02) 00507-1

Klatte, M., Schuler, M., Wirtz, M., Fink-Straube, C., Hell, R., and Bauer, P. (2009). The analysis of Arabidopsis nicotianamine synthase mutants reveals functions for nicotianamine in seed iron loading and iron deficiency responses. Plant Physiol. 150, 257-271. doi: 10.1104/pp.109.136374

Kobayashi, T., Ogo, Y., Itai, R. N., Nakanishi, H., Takahashi, M., Mori, S., etal. (2007). The transcription factor IDEF1 regulates the response to and tolerance of iron deficiency in plants. Proc. Natl. Acad. Sci. U.S.A. 104, 19150-19155. doi: 10.1073/pnas.0707010104

Koike, S., Inoue, H., Mizuno, D., Takahashi, M., Nakanishi, H., Mori, S., et al. (2004). OsYSL2 is a rice metalnicotianamine transporter that is regulated by iron and expressed in the phloem. Plant J. 39, 415424. doi: 10.1111/j.1365-313X.2004. 02146.x

Kou, X., Watkins, C. B., and Gan, S. S. (2012). Arabidopsis AtNAP regulates fruit senescence. J. Exp. Bot. 63, 6139-6147. doi: 10.1093/jxb/ ers266

Kutman, U. B., Yildiz, B., and Cakmak, I. (2011). Effect of nitrogen on uptake, remobilization and partitioning of zinc and iron throughout the development of durum wheat. Plant Soil 342, 149-164. doi: 10.1007/s11104010-0679-5

Lee, S., Jeon, U. S., Lee, S. J., Kim, Y. K., Persson, D. P., Husted, S. et al. (2009). Iron fortification of rice seeds through activation of the nicotianamine synthase gene. Proc. Natl. Acad. Sci. U.S.A. 106, 22014-22019. doi: 10.1073/pnas.0910950106

Lee, S., Kim, Y. S., Jeon, U. S. Kim, Y. K., Schjoerring, J. K., and An, G. (2012). Activation of rice nicotianamine synthase 2 (OsNAS2) enhances iron availability for biofortification. Mol. Cells 33, 269-275. doi: 10.1007/s10059-012-2231-3

Lee, S., Persson, D. P., Hansen, T. H., Husted, S., Schjoerring, J. K., Kim, Y. S., et al. (2011). Bio-available zinc in rice seeds is increased by activation tagging of nicotianamine synthase. Plant Biotechnol. J. 9, 865-873. doi: 10.1111/j.1467-7652.2011.00606.x

Lim, P. O., Kim, H. J., and Nam, H. G. (2007). Leaf senescence. Annu. Rev. Plant Biol. 58, 115-136. doi: 10.1146/annurev.arplant.57.032905. 105316

Lin, J. F., and Wu, S. H. (2004). Molecular events in senescing Arabidopsis leaves. Plant J. 39, 612-628. doi: 10.1111/j.1365-313X.2004.02160.x

Marschner, H. (1995). Mineral Nutrition of Higher Plants, 2nd Edn. London: Academic Press.

Masuda, H., Ishimaru, Y., Aung, M. S., Kobayashi, T., Kakei, Y., Takahashi, M., et al. (2012). Iron biofortification in rice by the introduction of multiple genes involved in iron nutrition. Sci. Rep. 2, 543. doi: 10.1038/ srep00543

Matile, P., Hortensteiner, S., Thomas, H., and Krautler, B. (1996). Chlorophyll breakdown in senescent leaves. Plant Physiol. 112, 1403-1409.

Nakashima, K., Takasaki, H., Mizoi, J., Shinozaki, K., and YamaguchiShinozaki, K. (2012). NAC transcription factors in plant abiotic stress responses. Biochim. Biophys. Acta 1819, 97-103. doi: 10.1016/ j.bbagrm.2011.10.005

Nakashima, K., Tran, L. S., Van Nguyen, D., Fujita, M., Maruyama, K., Todaka, D., et al. (2007). Functional analysis of a NAC-type transcription factor OsNAC6 involved in abiotic and biotic stress-responsive gene expression in rice. Plant J. 51, 617630. doi: 10.1111/j.1365-313X.2007. 03168.x

Nikovics, K., Blein, T., Peaucelle, A., Ishida, T., Morin, H., Aida, M., et al. (2006). The balance between the MIR164A and CUC2 genes controls leaf margin serration in Arabidopsis. Plant Cell 18, 2929-2945. doi: 10.1105/tpc.106.045617

Nishiyama, R., Kato, M., Nagata, S., Yanagisawa, S., and Yoneyama, T. (2012). Identification of $\mathrm{Zn}$-nicotianamine and $\mathrm{Fe}-2^{\prime}$ Deoxymugineic acid in the phloem sap from rice plants (Oryza sativa L.). Plant Cell Physiol. 53, 381-390. doi: $10.1093 /$ pcp/pcr 188

Ogo, Y., Itai, R. N., Kobayashi, T., Aung, M. S., Nakanishi, H., and Nishizawa, N. K. (2011). OsIRO2 is responsible for iron utilization in rice and improves growth and yield in calcareous soil. Plant Mol. Biol. 75, 593-605. doi: 10.1007/s11103-011-9752-6

Ohnishi, T., Sugahara, S., Yamada, T., Kikuchi, K., Yoshiba, Y., Hirano, H. Y., etal. (2005). OsNAC6, a member of the NAC gene family, is induced by various stresses in rice. Genes Genet. Syst. 80, 135-139. doi: 10.1266/ggs.80.135

Olmos, S., Distelfeld, A., Chicaiza, O., Schlatter, A. R., Fahima, T., Echenique, V., et al. (2003). Precise mapping of a locus affecting grain protein content in durum wheat. Theor. Appl. Genet. 107, 1243-1251. doi: 10.1007/s00122-003-1377-y

Olsen, A. N., Ernst, H. A., Leggio, L. L., and Skriver, K. (2005). NAC transcription factors: structurally distinct, functionally diverse. Trends Plant Sci. 10, 79-87. doi: 10.1016/j.tplants.2004.12.010

Palmgren, M. G., Clemens, S., Williams, L. E., Kramer, U., Borg, S., Schjorring, J. K., et al. (2008). Zinc biofortification of cereals: problems and solutions. Trends Plant Sci. 13, 464-473. doi: 10.1016/j.tplants.2008.06.005

Park, J., Kim, Y. S., Kim, S. G., Jung, J. H., Woo, J. C., and Park, C. M. (2011). Integration of auxin and salt signals by the NAC transcription factor NTM2 during seed germination in Arabidopsis. Plant Physiol. 156, 537549. doi: 10.1104/pp.111.177071

Prasad, A. S. (2012). Discovery of human zinc deficiency: 50 years later. J. Trace Elem. Med. Biol. 26, 66-69. doi: 10.1016/j.jtemb.2012.04.004

Puig, S., Andrés-Colás, N., GarcíaMolina, A., and Peñarrubia, L. (2007). Copper and iron homeostasis in Arabidopsis: responses to metal deficiencies, interactions and biotechnological applications. Plant Cell Environ. 30, 271-290. doi: 10.1111/j.1365-3040.2007.01642.x

Puranik, S., Sahu, P. P., Srivastava, P. S., and Prasad, M. (2012). NAC proteins: regulation and role in stress tolerance. Trends Plant Sci. 17, 369-381. doi: 10.1016/j.tplants.2012.02.004
Redillas, M. C. F. R., Jeong, J. S., Kim, Y. S., Jung, H., Bang, S. W., Choi, Y. D., et al. (2012). The overexpression of OsNAC9 alters the root architecture of rice plants enhancing drought resistance and grain yield under field conditions. Plant Biotechnol. J. 10, 792-805. doi: $10.1111 /$ j.14677652.2012.00697.x

Rolland, F., Baena-Gonzalez, E., and Sheen, J. (2006). Sugar sensing and signaling in plants: conserved and novel mechanisms. Annu. Rev. Plant Biol. 57, 675-709. doi: 10.1146/annurev.arplant.57.032905. 105441

Schuler, M., Rellán-Álvarez, R., FinkStraube, C., Abadía, J., and Bauer, P. (2012). Nicotianamine functions in the phloem-based transport of iron to sink organs, in pollen development and pollen tube growth in Arabidopsis. Plant Cell 24, 2380-2400. doi: 10.1105/tpc.112.099077

Shi, R., Weber, G., Köster, J., RezaHajirezaei, M., Zou, C., Zhang, F., et al. (2012). Senescence-induced iron mobilization in source leaves of barley (Hordeum vulgare) plants. New Phytol. 195, 372-383. doi: 10.1111/j.1469-8137.2012.04165.x.

Song, S. Y., Chen, Y., Chen, J., Dai, X. Y., and Zhang, W. H. (2011). Physiological mechanisms underlying OsNAC5-dependent tolerance of rice plants to abiotic stress. Planta 234, 331-345. doi: 10.1007/s00425011-1403-2

Souer, E., van Houwelingen, A., Kloos, D., Mol, J., and Koes, R. (1996). The no apical meristem gene of petunia is required for pattern formation in embryos and flowers and is expressed at meristem and primordia boundaries. Cell 85, 159170. doi: 10.1016/S0092-8674(00) 81093-4

Sperotto, R. A., Boff, T., Duarte, G. L., Santos, L. S., Grusak, M. A., and Fett, J. P. (2010). Identification of putative target genes to manipulate Fe and $\mathrm{Zn}$ concentrations in rice grains. J. Plant Physiol. 167, 1500-1506. doi: 10.1016/j.jplph.2010.05.003

Sperotto, R. A., Ricachenevsky, F. K., Duarte, G. L., Boff, T., Lopes, K. L., Sperb, E. R., et al. (2009). Identification of up-regulated genes in flag leaves during rice grain filling and characterization of OsNAC5, a new ABA-dependent transcription factor. Planta 230, 985-1002. doi: 10.1007/s00425-009-1000-9

Sperotto, R. A., Ricachenevsky, F. K., and Fett, J. P. (2007). Iron deficiency in rice shoots: identification of novel induced genes using RDA and possible relation to leaf senescence. 
Plant Cell Rep. 26, 1399-1411. doi: 10.1007/s00299-007-0330-y

Sperotto, R. A., Ricachenevsky, F. K., Waldow, V. A., and Fett, J. P. (2012a) Iron biofortification in rice: it's a long way to the top. Plant Sci. 190, 24-39. doi: 10.1016/j.plantsci.2012.03.004

Sperotto, R. A., Vasconcelos, M. W., Grusak, M. A., and Fett, J. P. (2012b). Effects of different Fe supplies on mineral partitioning and remobilization during the reproductive development of rice (Oryza sativa L.). Rice 5:27. doi: 10.1186/1939-8433-5-27

Takasaki, H., Maruyama, K., Kidokoro, S., Ito, Y., Fujita, Y., Shinozaki, K., et al. (2010). The abiotic stressresponsive NAC-type transcription factor OsNAC5 regulates stressinducible genes and stress tolerance in rice. Mol. Genet. Genomics 284, 173-183. doi: 10.1007/s00438-0100557-0

Thomas, H. (2013). Senescence, ageing and death of the whole plant. New Phytol. 197, 696-711. doi: 10.1111/nph.12047

Tran, L. S., Nakashima, K., Sakuma, Y., Simpson, S. D., Fujita, Y., Maruyama, K., et al. (2004). Isolation and functional analysis of Arabidopsis stress-inducible NAC transcription factors that bind to a droughtresponsive cis-element in the early responsive to dehydration stress 1 promoter. Plant Cell 16, 2481-2498. doi: 10.1105/tpc.104.022699

Uauy, C., Distelfeld, A., Fahima, T., Blechl, A., and Dubcovsky, J. (2006).
A NAC gene regulating senescence improves grain protein, zinc, and iron content in wheat. Science 314, 1298-1301. doi: 10.1126/science. 1133649

Wang, H., Zhao, Q., Chen, F., Wang, M., and Dixon, R. A. (2011). NAC domain function and transcriptional control of a secondary cell wall master switch. Plant J. 68, 1104 1114. doi: 10.1111/j.1365-313X.2011. 04764.x

Waters, B. M., Chu, H. H., Didonato, R. J., Roberts, L. A., Eisley, R. B., Lahner, B., et al. (2006). Mutations in Arabidopsis yellow stripelike1 and yellow stripe-like3 reveal their roles in metal ion homeostasis and loading of metal ions in seeds. Plant Physiol. 141, 1446-1458. doi: 10.1104/pp.106.082586

Waters, B. M., and Grusak, M. A. (2008) Whole-plant mineral partitioning throughout the life cycle in Arabidopsis thaliana ecotypes Columbia, Landsberg erecta, Cape Verde Islands, and the mutant line ysllysl3. New Phytol. 177, 389-405.

Waters, B. M., Uauy, C., Dubcovsky, J., and Grusak, M. A. (2009). Wheat (Triticum aestivum) NAM proteins regulate the translocation of iron, zinc, and nitrogen compounds from vegetative tissues to grain. J. Exp. Bot. 60, 4263-4274. doi: 10.1093/jxb/erp257

White, P. J., and Broadley, M. R. (2005). Biofortifying crops with essential mineral elements. Trends
Plant Sci. 10, 586-593. doi: 10.1016/j.tplants.2005.10.001

Wingler, A., von Schaewen, A., Leegood, R. C., Lea, P. J., and Quick, W. P. (1998). Regulation of leaf senescence by cytokinin, sugars, and light. Effects on NADH-dependent hydroxypyruvate reductase. Plant Physiol. 116, 329-335. doi: 10.1104/pp.116. 1.329

Wirth, J., Poletti, S., Aeschlimann, B., Yakandawala, N., Drosse, B., Osorio, S., et al. (2009). Rice endosperm iron biofortification by targeted and synergistic action of nicotianamine synthase and ferritin. Plant Biotechnol. J. 7, 631-644. doi: 10.1111/j.14677652.2009.00430.x

Xie, Q., Frugis, G., Colgan, D., and Chua, N. H. (2000). Arabidopsis NAC1 transduces auxin signal downstream of TIR1 to promote lateral root development. Genes Dev. 14, 3024-3036. doi: 10.1101/gad. 852200

Yoshida, S. (2003). Molecular regulation of leaf senescence. Curr. Opin. Plant Biol. 6, 79-84. doi: 10.1016/S1369526602000092

Zavaleta-Mancera, H. A., Franklin, K. A., Ougham, H. J., Thomas, H., and Scott, I. M. (1999). Regreening of senescent Nicotiana leaves. I. Reappearance of NADPH protochlorophyllide oxidoreductase and light-harvesting chlorophyll a/bbinding protein. J. Exp. Bot. 50, 1677-1682. doi: 10.1093/jxb/50.340. 1677
Zhang, C. D., Romheld, V., and Marschner, H. (1995). Retranslocation of iron from primary leaves of bean plants grown under iron deficiency. J. Plant Physiol. 146, 268272. doi: 10.1016/S0176-1617(11) 82052-3

Conflict of Interest Statement: The authors declare that the research was conducted in the absence of any commercial or financial relationships that could be construed as a potential conflict of interest.

Received: 12 March 2013; accepted: 10 June 2013; published online: 01 July 2013. Citation: Ricachenevsky FK, Menguer $P K$ and Sperotto RA (2013) kNACking on heaven's door: how important are $N A C$ transcription factors for leaf senescence and $\mathrm{Fe} / \mathrm{Zn}$ remobilization to seeds? Front. Plant Sci. 4:226. doi: 10.3389/ fpls.2013.00226

This article was submitted to Frontiers in Plant Physiology, a specialty of Frontiers in Plant Science.

Copyright (C) 2013 Ricachenevsky, Menguer and Sperotto. This is an open-access article distributed under the terms of the Creative Commons Attribution License, which permits use, distribution and reproduction in other forums, provided the original authors and source are credited and subject to any copyright notices concerning any third-party graphics etc. 